\title{
Economia Solidária e Feminista: apontamentos sobre a representação social do trabalho doméstico pelas mullheres de Araguaína/TO
}

\author{
Solidarity Economy and Feminist: notes on the social representation of \\ domestic work by women of Araguaína / TO
}

\author{
Economía Solidaria y Feminista: notas sobre la representación social \\ del trabajo doméstico de las mujeres de Araguaína / TO
}

\author{
Renata Rauta Petarly \\ Universidade Federal do Tocantins, Brasil \\ renatapetarly@uft.edu.br
}

\section{Resumo}

A pesquisa teve como objetivo fazer apontamentos sobre como as mulheres residentes de setores periféricos do interior do estado do Tocantins, Brasil, percebem o trabalho doméstico. Foi utilizado para isso a teoria das representações coletivas e da divisão sexual do trabalho. As entrevistas aconteceram durante cursos de capacitação oferecidos por um programa de extensão universitária vinculado à Universidade Federal do Tocantins. Os resultados apontaram que o trabalho doméstico ainda é tido como de responsabilidade apenas das mulheres da casa e que a divisão estabelecida entre trabalho público e trabalho privado não é dessa forma porque as mulheres gostam do trabalho doméstico, mas, sim, por serem determinadas à execução dessas funções.

Palavras-Chave: Trabalho Doméstico; Economia Feminista; Divisão Sexual do Trabalho.

\begin{abstract}
The research aimed to make notes about how women living in peripheral areas of the interior of the state of Tocantins, Brazil, realize the housework. Was used for this theory of collective representations and the sexual division of labor. The interviews took place during training courses offered by a university extension program linked to the Federal University of Tocantins . The results showed that domestic work is still seen as the responsibility of only the women of the house and that the established division between public and private work is not work that way because women like domestic work, but because they are determined to these functions.
\end{abstract}

Keywords: Housework; Feminist Economics; Sexual Division of Labor.

\section{Resumen}

La investigación tuvo como objetivo tomar notas sobre cómo las mujeres que viven en zonas periféricas del interior del estado de Tocantins, Brasil, perciben el trabajo doméstico. Se utilizó la teoría de las representaciones colectivas y de la división sexual del trabajo. Las entrevistas se llevaron a cabo durante cursos de capacitación ofrecidos por un programa de extensión universitaria vinculado a la Universidad Federal de Tocantins. Los resultados mostraron que el trabajo doméstico sigue siendo visto como responsabilidad única de las mujeres de la casa y que la división establecida entre trabajo público y trabajo privado no es así porque a las mujeres les guste el trabajo doméstico, sino porque están determinadas a la ejecusión de estas funciones.

Palabras-Clave: Trabajo Doméstico; Economía Feminista; División Sexual del Trabajo. 


\section{Introdução}

O presente artigo tem como objetivo fazer apontamentos sobre como as mulheres residentes de setores periféricos do município de Araguaína, Tocantins, percebem o trabalho doméstico e como isso se vincula à lógica da economia e da divisão sexual do trabalho. Para isso, fizemos um referencial conceitual com autores que apresentam como a economia solidária e como a economia feminista podem se tornar uma forma de se estruturar o sistema econômico hegemônico, baseado no androcêntrismo em um sistema que se paute no desenvolvimento igualitário a partir da melhoria da qualidade de vida.

A pesquisa se deu em cursos de capacitação para Associações de Bairro do município, integrantes do programa de extensão universitária 'Implantação da incubadora tecnológica de cooperativas populares', da Universidade Federal do Tocantins (ITCP/UFT) e utilizou como metodologia a teoria das representações coletivas. Foram entrevistadas 16 mulheres que elencaram o que o trabalho doméstico significavam para elas.

\section{Economia Solidária e Feminista}

Surgida no século passado, a economia solidária é uma proposta de reorganizar os métodos produtivos e de comercialização por meio do trabalho coletivo e de regras específicas que se diferem do atual modelo econômico. De acordo com Guérin (2005, p. 13), a economia solidária "agrupa o conjunto das iniciativas econômicas privadas (isto é, autônomas em relação ao Estado), que apostam mais no interesse coletivo e na solidariedade que na busca do lucro".

É possível identificar inúmeras experiências de sucesso da economia solidária em diversos setores produtivos. Alcântara (2005) explica que podemos chamar de economia solidária,

todos os empreendimentos que, embora tenham formas e classificações diversas, possuam como característica comum a solidarização de capital e a autogestão. As organizações que compõem a assim chamada Economia Solidária contemplam desde mutirões, associações das mais diversas, cooperativas de todos os tipos, grupos de pequenos produtores, etc. Todas elas prestam não apenas serviços como também podem constituir-se enquanto organizações produtivas e de consumo. (ALCÂNTARA, 2005, p. 69).

Essa estratégia, de acordo com Singer (2002), pode se constituir como uma alternativa à incapacidade do capitalismo de promover a junção entre a demanda e a oferta de trabalho. Isso significa dizer que a economia solidária pode ser "uma alternativa superior ao capitalismo. (...) A economia solidária foi concebida para ser uma alternativa superior por proporcionar às pessoas que a adotam, enquanto produtoras, poupadoras, consumidoras, etc., uma vida melhor" (SINGER, 2002, p. 114).

Nesse sentido, o que o autor apresenta é que a economia solidária possibilita aos seus envolvidos, uma liberdade de escolha que não é possível no sistema capitalista. No sistema hegemônico, por não haver igualdade entre os sujeitos, são facilmente produzidos sistemas desiguais de produção, consumo e trabalho o que acarreta nas correntes desigualdades da vida social, econômica e política. A solução para esses problemas viria, então, de uma economia que pensasse (ao invés da competição e do individualismo) na solidariedade, a cooperação e a igualdade 
como seus pilares de sustentação.

Santos (s/d) complementa que apesar do sistema capitalista produzir inúmeras desigualdades, não podemos restringi-las apenas ao viés econômico. Dentro das desigualdades limitadoras da liberdade dentro do sistema capitalista, encontramos as desigualdades de gênero, raça, idade e etnia. Alguns autores, como Lobo, citada por Cisne (2002), acreditam que

a homogeneização da classe, consequência de sua construção como elemento estrutural, se traduz numa metodologia de aproximação em que não cabe a abordagem concreta das situações de trabalho e, face ao trabalho e à sociedade, da vida cotidiana e das relações que estabelecem homens e mulheres ao vivenciarem as relações de produção, e experimentarem situações determinadas, dentro do conjunto das relações sociais (LOBO, 1991, p. 117).

Essa compreensão androcêntrica da classe leva a não valorização do trabalho executado pelas mulheres. Para Cisne (2012), essa situação desencadeia na falta da construção da identidade de classe trabalhadora, resultando na desmobilização, acomodação e falta de participação na vida política da classe trabalhadora que sofrem com várias consequências emitentes do sistema capitalista, como o desemprego, a desvalorização salarial e as más condições de trabalho. Essa mesma autora defende, ainda, que nessa situação, as mulheres "deixam também de assumir cargos em associações, sindicatos ou na direção de movimentos sociais, o que contribui diretamente com o capital, pois significa menos pessoas em confronto com este sistema" (CISNE, 2012, p. 114).
Nessa conjuntura, após diversas conquistas referentes ao trabalho da mulher, a economia solidária se torna tema de discussão de diversos grupos feministas por acreditar que esta seja uma alternativa para estabelecer novas relações econômicas entre o próprio gênero feminino, como em relação com o gênero masculino. A economia solidária, assim, reconhece como igual e questiona a atual divisão sexual do trabalho. Dessa forma, Moreno (2012, p. 131) explica que

neste sentido, o reconhecimento dos direitos sociais do trabalho associado é uma demanda, mas também o questionamento da divisão sexual do trabalho, tanto no que se refere a relação entre reprodução e produção, quanto na divisão do trabalho produtivo, que por vezes reserva às mulheres as tarefas tradicionalmente consideradas femininas (MORENO, 2012, p. 131).

Importante lembrar que a situação vivenciada pelas mulheres, no mercado de trabalho, nos remete a subordinação da mulher e a designação de qual trabalho desempenhar é vinculado aos seus dons e suas habilidades, determinadas como femininas. Para Cisne (2012), essa situação leva o capital a se apropriar da força de trabalho feminina como se fosse um dom, e não como o trabalho que de fato o é. A consequência disso é o sistema capitalista caracterizar o trabalho $\mathrm{e}$ as atividades 'feminilizadas', como uma tarefa menos complexa, justificando o desprestígio e a desvalorização da força de trabalho feminino. Neste mesmo sentido, Louro (2011) acredita, inclusive, que a desigualdade social existente na sociedade é decorrente dessa naturalização da distinção dos papeis sociais serem 
provenientes da explicação biológica da distinção sexual entre homens e mulheres.

$\mathrm{O}$ argumento de que homens e mulheres são biologicamente distintos e que a relação entre ambos decorre dessa distinção, que é complementar e na qual cada um deve desempenhar um papel determinado secularmente, acaba por ter o caráter de argumento final, irrecorrível. Seja no âmbito do senso comum, seja revestido por uma linguagem "científica", a distinção biológica, ou melhor, a distinção sexual, serve para compreender - e justificar - a desigualdade social (LOURO, 2011, 24).

É nesse panorama que a diversas autoras e autores se debruçam em uma corrente teórica que busca compreender e estruturar o sistema econômico por meio da economia feminista. A proposta dessa economia é incluir a discussão de gênero dentro da macroeconomia, "com intenção de promover mudança radical na análise econômica, em seus pressupostos básicos e metodologias" (SANTOS, s/d, p. 1). Essa inclusão permite que se questione a presença das mulheres nas estatísticas econômicas mundiais apenas como pertencente aos critérios familiares, ficando seu olhar sobre a economia e sua participação nela invisíveis em suas análises e em suas propostas de mudança.

Após o levantamento de várias críticas em relação a essa invisibilidade, órgãos internacionais como o Fundo Monetário Internacional e o Banco Mundial passaram a incluí-las em suas análises, mas reconhecendo as mulheres apenas como as responsáveis pelos trabalhos de cuidados (de crianças, idosos e adultos dependentes) e pela reprodução familiar. Delimitando-as, assim, apenas ao espaço doméstico e a excluindo esse papel do ambiente econômico e mercadológico.

Os estudos da economia feminista nos levam a algumas inovações teóricas importantes que desafiam as categorias conceituais econômicas tradicionais de individualidade, atividade, família e trabalho. Como resultado disso, é possível perceber a desconstrução da relação direta estabelecida entre os valores sociais e o ambiente do mercado, e uma nova forma de se compreender a vida econômica valorizando as contribuições negligenciadas nos resultados econômicos provenientes do trabalho das mulheres (STRASSMANN, 2012). Trabalho este que, por não ser vendido, não se incorpora aos ganhos econômicos.

Relacionado a esse trabalho está o reconhecimento de que as relações familiares e outras interpessoais são, elas próprias, frequentemente construídas e mantidas por meio de atividades específicas valiosas, como cuidar das necessidades materiais e emocionais da família. Contudo, por não serem vendidas, essas atividades foram desprezadas pelos economistas e de maneira mais geral por sociedades patriarcais nas quais os homens tem mais poder para incorporar valores sociais nas estruturas institucionais (STRASSMANN, 2012, p. 31).

O que precisa ser feito, de acordo com a economia feminista e a economia solidária, é a reconfiguração do que é trabalho valorizado/não valorizado. A ideia é a proposição de novas categorias analíticas que compreendam o trabalho remunerado/não remunerado, produtivo/não produtivo para além da sua atual conceitualização binária de valor/não valor. Para fazer um recorte 
analítico, abordaremos no próximo tópico como o trabalho doméstico se insere nessa discussão e adiante como a representação social influencia na determinação desse papel na sociedade.

\section{O Trabalho Doméstico}

Com a atuação dos movimentos feministas, que buscam constantemente a igualdade entre os gêneros, é possível perceber mudanças nessa dicotomia instaurada pelo sistema capitalista e a economia feminista torna notória a participação das mulheres na economia, tendo como tema legítimo o trabalho de maneira mais ampla, incluindo, assim, a divisão sexual do trabalho na família, no mercado informal, no trabalho doméstico, associando assim a educação e demais características ligada a Economia.

No Brasil a autonomia econômica das mulheres está ligada a salários justos, a trabalhos digno e a previdência social e aos serviços públicos. $\mathrm{Na}$ visão feminista, a divisão sexual do trabalho, está ligada à exclusão e à pobreza, pois são acontecimentos que afeta de forma desigual os sexos (FARIA, 2012, p. 7).

Percebe-se, assim, que isso serviu para mostrar que o discurso sobre igualdade entre os sexos é muito mais antigo e como afirma Puleo (2012, p. 15), "estudo do discurso Filosófico nos mostra que muitas vezes - ou quase sempre -, quando há um discurso profundamente misógino é porque paralelamente existe um discurso feminista". Isso mostra que as mulheres, além de se afirmarem como sujeitos políticos, utilizam a teoria feminista para recuperarem parte da história que foi deixada de lado para impossibilitar o aparecimento e a contribuição das mulheres.

Um dos principais fatores do trabalho feminino aparecer como complemento da renda familiar vem da herança deixada pela sociedade patriarcal que na maioria das vezes estimulou a divisão sexual do trabalho, consolidando, assim, a divisão entre a presença e as atividades desenvolvidas no setor público (o da produção mercantil e da tomada de decisões), destinado aos homens e o modelo privado (não mercantil, da família e da maternidade), destinado às mulheres. Nesse sentido, como já apresentado anteriormente, aos homens eram destinados às atividades que agregavam maior valor $\mathrm{e}$ para as mulheres eram destinadas as tarefas domésticas.

Essa situação destina às mulheres o papel social da maternidade e do cuidado, que resulta na definição do seu lugar no mundo. No entanto, isso nada mais é, que um discurso afirmativo de que as mulheres só se inserem no mundo porque parte de suas qualidades, virtudes e capacidades são definidas como a partir da sua natureza de serem capazes de gerar novas vidas.

A realização de trabalhos de cuidados está, portanto, relacionada a normas sociais e identidades, como a construção social da maternidade e a suposição de que as mulheres mães desempenham atividades de cuidados essencialmente motivadas pelo sentimento de amor. Essa suposição, profundamente vinculada às relações sociais de sexo, desconsidera o conteúdo econômico e a própria característica de trabalho que os cuidados constituem. Esta é, inclusive, uma forma de se perpetuar uma organização social dos cuidados que mantém as mulheres, e seu altruísmo, realizando uma 
grande quantidade de trabalho necessário, porém invisível (MORENO, 2012, p. 59).

Neste contexto, a discussão sobre o trabalho doméstico aparece em autoras como Dalla Costa e Carrasco, apresentadas por Moreno (2012, p. 57), como atividade produtiva "na medida que reproduz a mercadoria força de trabalho" o que responsabiliza, ainda mais, as mulheres ao âmbito privado. No entanto, autoras como Elson (1994, p.40) defendem que "a capacidade do dinheiro de mobilizar a força de trabalho a serviço do 'trabalho produtivo' depende de que um conjunto de relações sociais opere para mobilizar a força de trabalho a serviço do "trabalho reprodutivo"". Moreno (2012, p. 58) utiliza Kergoat (1996) para explicar que "esta formulação dialoga com a definição de relações sociais de sexo, que atravessam todo o campo social e são materialmente sustentadas pela divisão sexual do trabalho".

A sistematização feita por Moreno (2012) nos leva a concluir que o trabalho doméstico se torna reconhecido quando há a mediação do dinheiro em seu exercício. Assim, apenas quando o trabalho doméstico é contratado e devidamente remunerado, é que ele se torna uma categoria de trabalho existente na economia neoclássica. Importante destacar que a pesquisa realizada pelo PNUD (2009), identifica que $93 \%$ do emprego doméstico eram exercidos por mulheres e que destas, $61,7 \%$ eram mulheres negras. As famílias contratantes eram aquelas de classe média e alta em que as mulheres conseguiram se inserir no espaço público de maneira semelhante aos homens.

$\mathrm{O}$ que se nos propomos a discutir neste momento, é como a não mercantilização do trabalho doméstico se estabelece nas famílias e como isso é percebido pelas mulheres que o executam. Diversas autoras da economia feminista buscam a compreensão e a teorização do trabalho doméstico tendo como base os paradigmas da corresponsabilidade, conciliação e delegação ${ }^{1}$.

Por corresponsabilidade se compreende a divisão deste trabalho entre os membros da família. A conciliação se dá quando a pessoa responsável pelo trabalho doméstico e de cuidados, não remunerado, concilia este com o trabalho remunerado. Por sua vez, a delegação se refere a delegação deste trabalho para uma pessoa de fora da família, como uma empregada doméstica ou cuidadora. $\mathrm{O}$ paradigma da conciliação tende a predominar em sociedades que não distribuem o trabalho doméstico e de cuidados entre homens e mulheres no interior das famílias e entre família e Estado. (MORENO, 2012, p. 75)

A proposta, apresentada pela economia feminista, é que o trabalho doméstico seja de corresponsabilidade entre todos os membros da família. Seria possível, assim, que a divisão sexual do trabalho através da binariedade público/privado, seja alterada. Este é o motivo que leva a economia feminista e solidária a tentarem a reorganização do atual modelo econômico hegemônico. Para isso, é preciso que se refaça a ideia de homem-provedor e mulherdona de casa $^{2}$ e que o Estado assuma as responsabilidades do cuidado designadas às mulheres. Dessa forma, além de haver a corresponsabilidade no trabalho doméstico, é possível que haja a conciliação do trabalho no espaço público com os trabalhos do espaço privado.

\section{Representação Social}


Economia solidária e feminista: apontamentos sobre a representação social do trabalho doméstico pelas mulheres de Araguaína - T0

Várias teóricas feministas utilizam o aporte da teoria das representações sociais para compreender a forma como a sociedade e as próprias mulheres compreendem os papeis a elas atribuídos. Compreender a representação coletiva que se tem acerca de um determinado tema, nos exige entender como esse processo se constrói e se constitui no pensamento do grupo com o qual estamos trabalhando. Como o caso em análise se propõe a averiguar qual a representação coletiva das mulheres araguainenses sobre o trabalho doméstico, primeiramente se torna necessário compreendermos como essa Teoria se constitui e como ela pode contribuir para nossas reflexões acerca do nosso objeto de estudo. A partir dessa percepção é que compreendemos a forma como as próprias mulheres reproduzem a estrutura patriarcal e a dualidade entre publico/privado.

Inicialmente, é importante termos como base os estudos que Marcel Mauss e Emile Durkheim $^{3}$ fizeram sobre as formas primitivas de classificação nas sociedades. $\mathrm{O}$ que esses autores nos apresentam, é que as classificações das coisas não são feitas de maneiras isoladas, mas sim, levam-se em consideração as relações estabelecidas entre os grupos que se transformam em determinados conjuntos. Ressalta-se que a relação estabelecida não se dá apenas por características naturais ou lógicas, mas sim pelas interações sociais que esses grupos estabelecem em determinado meio. Assim, esses sistemas possuem uma finalidade especulativa, de fazer compreender determinado objeto por meio da compreensão das relações existentes entre os seres (MAUSS, 1999, p. 450). Dessa forma, o que os autores nos mostram é que a compreensão da sociedade é realizada por meio da estrutura que os indivíduos classificam os elementos constituintes dessa sociedade.

E se a totalidade das coisas é concebida como um sistema uno, é porque a própria sociedade é concebida da mesma maneira. Ela é um todo, ou antes, ela é o todo único ao qual tudo é referido. Assim, a hierarquia lógica não é mais do que outro aspecto da hierarquia social e a unidade do conhecimento não é outra coisa senão a própria unidade da coletividade, estendida ao universo. (MAUSS, 1999, p. 452)

A partir dessa compreensão sobre as formas que utilizamos para fazermos as classificações do que constitui a sociedade em que vivemos, Denise Jodelet (2001) nos mostra como as Representações Sociais contribuem nesse processo de compreensão da realidade que habitamos. Para ela, "representar ou se representar corresponde a um ato de pensamento ao qual um sujeito se reporta a um objeto" (JODELET, 2001, p. 22). Dessa forma, o que a autora tenta nos mostrar no decorrer do seu trabalho, é que criamos as representações como forma de nos ajudar a nos organizarmos e nos ajustarmos ao mundo que nos cerca, pois "precisamos saber como nos comportar, dominá-lo física ou intelectualmente, identificar e resolver problemas que se apresentam" (JODELET, 2001, p. 17). Assim, as representações sociais são "uma forma de conhecimento socialmente elaborado e compartilhado, com um objetivo prático, e que contribui para a construção de uma realidade comum a um conjunto social" (JODELET, 2001, p. 22).

De acordo com a mesma autora, as representações sociais são constituídas tendo como base os valores sociais que podem ser variáveis ou saberes anteriores. As representações, assim, estão relacionadas a sistemas de pensamentos que se caracterizam como amplos e refletidos de maneira ideológica e cultural, relacionadas também ao 
conhecimento científico de determinado grupo, à condição social do mesmo e às experiências, tanto privadas individuais quanto afetivas desse próprio indivíduo.

(...) as representações expressam aqueles (indivíduos ou grupos) que as forjam e dão uma definição específica ao objeto por elas representado. Estas definições partilhadas pelos membros de um mesmo grupo constroem uma visão consensual da realidade para esse grupo. Esta visão, que pode entrar em conflito com a de outros grupos, é um guia para as ações e trocas cotidianas - trata-se das funções e da dinâmica sociais das representações (JODELET, 2001, p. 21).

Vale ressaltar que o conceito de representação social passou por diversas mudanças no decorrer de sua trajetória devido à transversalidade de abordagens que a utilizam. Citando Moscovici (1976), Jodelet (2001) afirma que o conceito se encontra em uma encruzilhada entre a sociologia e a psicologia social, onde é fundamental que o pesquisador leve em consideração as especificidades do grupo ao qual analisa como as interações, estrutura e evolução das representações, juntamente com o funcionamento cognitivo e o aparelho psíquico dos indivíduos desse próprio grupo. A autora também reitera a necessidade da análise da representação ser feita levando em consideração questões afetivas, emocionais, estruturais, mentais e sociais, compilando-os em uma análise comunicacional, da linguagem e da cognição. Para ela, o que difere o estudo das representações sociais dos estudos de caráter puramente cognitivista ou clínica da psicologia, é a perspectiva de "integrar na análise desses processos a pertença e a participação, sociais ou culturais do sujeito" (JODELET, 2001, p. 27). Nesse sentido, Mauss e Durkheim afirmam ainda que "uma espécie de coisas não é um simples objeto de conhecimento, mas corresponde antes de tudo a uma certa atitude sentimental" (MAUSS, 1999, p. 452). Eles defendem que "é este valor emocional das noções que desempenha o papel preponderante na maneira pela qual as ideias se aproximam ou se separam. É ela que serve de caráter dominador na classificação" (MAUSS, 1999, p. 454). Assim, não é possível determinar as classificações de maneiras isoladas, categorizando-as com rigor, visto que as mesmas são feitas com caráter emocional, onde não sabemos onde começa ou termina determinada categoria.

Dito isso, percebo que a contribuição dos estudos das representações sociais se consolida na compreensão das formas de atuação no mundo de acordo com a perspectiva individual, construída coletivamente, da maneira ao qual determinado individuo enxerga por meio das classificações, e representa o objeto no qual ele intervém. A partir daí, temos que "ao contrário do paradigma informático, que recobre todo o esforço científico sob a capa de uma mesma forma, o modelo das representações sociais, impulsiona a diversidade e a invenção, traz o desafio da complexidade" (JODELET, 2001, p. 41). Assim, a autora nos possibilita compreender a participação humana nas suas relações sociais com vias à complexidade dessas interações, onde o agir não se entende apenas por critérios cognitivos das estruturas mentais, mas sim, a partir de uma gama complexa de elementos constituintes e construídos durante essas relações.

\section{Procedimentos Metodológicos}

Esta é uma pesquisa exploratória que busca identificar qual a percepção que as mulheres araguainenses possuem do trabalho 
doméstico. É um estudo de representação social, onde as entrevistadas responderam a um roteiro estruturado de entrevista, no qual deveriam elencar palavras que a remetessem à determinadas palavras.

A pesquisa é parte de um projeto de extensão da Universidade Federal do Tocantins com o Ministério da Educação, por meio do edital Proext/2014 que tem como objetivo a constituição de uma incubadora tecnológica de cooperativas populares no curso de Tecnologia em Gestão de Cooperativas na UFT/Campus Araguaína. Compondo o projeto, foram realizados diversos cursos de capacitação com o público principal as respostas variam entre: estudantes, atividades de cuidado (como saúde e limpezas diversas) e trabalhos externos com carteira assinada (corretora de seguros e vigilante).

\section{Análise dos Resultados}

O estudo de representação social teve com norteador diversas expressões chaves onde as mulheres foram indagadas: "Qual é a primeira coisa que lhe vem à mente quando vê as seguintes expressões?".

Quando questionadas sobre o trabalho doméstico, as respostas foram as seguintes:

Quadro 1: Representação social sobre o trabalho doméstico

\begin{tabular}{|l|l|}
\hline \multicolumn{1}{|c|}{ O que é trabalho doméstico? } & \multicolumn{2}{c|}{ Percentual de respondentes } \\
\hline Representação positiva & $12,5 \%$ \\
\hline Representação negativa & $31,25 \%$ \\
\hline Regulamentação & $12,5 \%$ \\
\hline Descrição da atividade & $25 \%$ \\
\hline Responsabilidade das mulheres & $12,5 \%$ \\
\hline Responsabilidade da família & $6,25 \%$ \\
\hline
\end{tabular}

Fonte: Elaborado pela autora com base nos dados da pesquisa.

alvo do projeto, que são os residentes de setores da periferia do município. Assim, os dados apresentados neste artigo são referentes às mulheres que participaram dos cursos de: participação social: o que as mulheres têm a o ver com isso?; Economia solidária; Relação pai e filhos e Captação de Recursos para Associações.

Foram entrevistadas 16 mulheres com faixa etária entre 17 e 55 anos e com renda familiar per capita entre $\mathrm{R} \$ 166,00$ a $\mathrm{R} \$ 1.000,00$ mensais. Destas, apenas duas recebem algum auxílio governamental, como o Bolsa Família e Bolsa Jovem. E em sua maioria $(68,75 \%)$ são mulheres solteiras. Quando questionadas sobre sua ocupação
Esse agrupamento de respostas nos leva a perceber a forma como essas mulheres percebem o trabalho por elas desenvolvido. Em sua totalidade, a responsável pelo trabalho doméstico, em suas famílias, executa-o. No entanto, apesar de todas o executarem, $31,25 \%$ das respondentes não gostam do trabalho doméstico. As respostas variaram entre 'cansativo', 'estressante' ou 'deveria deixar de existir', mas apenas 6,25\% expõem que este deveria ser um trabalho compartilhado com toda a família.

Essa representação nos leva a perceber que por mais desgastante que seja, o trabalho doméstico ainda é tido como de responsabilidade apenas das mulheres da 
casa. Além disso, que o trabalho doméstico não é exercido pelas mulheres por elas terem naturalmente as aptidões ou o perfil para executar essas funções, conforme é difundido pela sociedade ou pela estrutura patriarcal da sociedade. Notamos, dessa forma, que a divisão estabelecida entre trabalho público (masculino) e trabalho privado (feminino) não é dessa forma porque as mulheres gostam do trabalho doméstico, mas sim por serem determinadas à execução dessas funções.

Ao analisarmos, ainda, o perfil das respondentes, notamos que em sua maioria, as mulheres exercem, no espaço público, atividades que reproduzem o trabalho do espaço privado como as profissões relacionadas aos cuidados: ligados à área da saúde (enfermagem, agente de saúde) ou da limpeza (lavadeira, serviços gerais).

\section{Considerações Finais}

A partir da bibliografia apresentada, tentamos desconstruir a naturalização do trabalho doméstico como atividade definida como trabalho feminino e como isso se constitui como atividade produtiva e desvalorizada no atual sistema econômico.

Para isso, apresentamos como mulheres pertencentes a classes populares do município de Araguaína, no estado do Tocantins, percebem e representam essa atividade em suas vidas. Notamos que a opinião das mesmas corrobora com a teoria apresentada de que o trabalho não deve ser definido como trabalho das mulheres, pois o mesmo não é escolhido pelas próprias mulheres.

Analisar a representação social que as mulheres fazem de determinada atividade é crucial para entender a forma como elas se posicionam e estabelecem suas vidas na sociedade. Assim, é possível compreendermos, com ajuda da teoria, a forma como a economia hegemônica determina, por uma visão androcêntrica, a vida das mulheres. A proposta de se construir uma economia solidária e feminista se torna crucial para que o estabelecimento da economia na sociedade seja feito com o olhar da igualdade macroeconômica, e não do fortalecimento da divisão sexual do trabalho. Assim, talvez, o olhar para o desenvolvimento possa ser vinculado à melhoria da qualidade de vida e o trabalho doméstico e de cuidados possa ser compartilhado e valorizado por toda sociedade.

1 Para melhor compreensão, vide HIRATA, Helena; KERGOAT, Danièle. "Novas configurações da divisão sexual do trabalho". Cadernos de Pesquisa, v. 37, n. 132, 2007.

2 A pesquisa do IBGE de 2011 apresenta dados conclusivos sobre essa situação. Nas famílias entrevistadas, as mulheres relataram gastar 27,7 horas semanais com o trabalho doméstico, enquanto que os homens se dedicavam apenas 11,2 horas semanais à essas atividades.

3 Este estudo foi feito em 1903 e foi extraído de Année sociologique, 6. [Oeuvres, v. II, pp. 13-89].

\section{Referências}

ALCÂNTARA, Fernanda Henrique Cupertino. Economia solidária: o dilema da institucionalização. São Paulo: Arte \& Ciência, 2005. 167p.

CISNE, Mirla. Gênero, Divisão sexual do trabalho e serviço social. São Paulo: Outras Expressões, 2012.

ELSON, Diane. People, development and international financial institutions: an interpretation of the Bretton Woods system. Review of African Political Economy, v. 21, 
n. 62, p. $511-524,1994$.

FARIA, Nalu. Perspectivas feminista para a igualdade e autonomia das mulheres. Capitalismo e patriarcado: um só modelo? São Paulo, 2012, p.07.

GUÉRIN, Isabelle. As mulheres e a economia solidária. Tradução Nicólas Nyimi Campanário. São Paulo: Edições Loyola, 2005.

JODELET, Denise. As representações sociais. Rio de Janeiro: EdUERJ, 2001.

KERGOAT, Danielle. Relações sociais de sexo e divisão sexual do trabalho. In: LOPES, Marta et al. Gênero e saúde. São Paulo: Ed. Artes Médicas, 1996.

LOURO, Guacira. Lopes. Gênero, sexualidade e educação: uma perspectiva pós estruturalista. Petrópolis, RJ: Editora Vozes, 2011.

MAUSS, Marcell; DURKHEIM, Emile. Contribuição para o estudo das representações coletivas (1903). In: MAUSS, Marcell. Ensaios de Sociologia. São Paulo: Editora Perspectiva, 1999, p. 399 - 455.

MORENO, Renata Faleiros Camargo. Além do que se vê: uma leitura das contribuições do feminismo para a economia. 2012. Dissertação (Programa de Pós-Graduação em Ciências Humanas e Sociais) - Universidade Federal do ABC, São Paulo.

MORENO, Renata Faleiros Camargo (Org.) Perspectivas Feminista Para a Igualdade e Autonomia das Mulheres. A luta feminista e seus desafios. São Paulo. 2012.

SAFFIOTI, Heleieth. Gênero, patriarcado e violência. São Paulo: Editora Fundação Perseu Abramo, 2004.

SANTOS, Graciete. Economia Solidária e Feminista: um encontro possível. Disponível em: $<$ http://www.fbes.org.br/biblioteca22/econom ia_feminista_um_encontro_poss $\%$ Edvel $>$. Acesso em 16 de Outubro de 2014.

STRASSMANN, Diane. A economia feminista. In: FARIA, Nalu; NOBRE, Miriam (Org.). Economia Feminista. Cadernos sempreviva. São Paulo: SOF, 2002.
Recebido em 26 de agosto de 2015. Aceito em 19 de dezembro de 2015. 